\title{
EL CABALLERO BERENGUER DE PUIGMOLTÓ, GUERRERO Y FUNCIONARIO AL SERVICIO DE JAIME II
}

\author{
Pedro Carlos PICATOSTE NAVARRO \\ Universidad de Alicante
}

\begin{abstract}
«... Un hombre también se ennoblece si sigue la profesión de las armas como luchador y siguiendo al príncipe valerosamente y durante mucho tiempo en la guerra..."
\end{abstract}

Esta cita de Olivier de la Marche ${ }^{2}$, clásica en los temas de caballería, nos sirve como introducción para el estudio de uno de los caballeros que acompañan al rey Jaime II en su campaña sobre el antiguo reino de Murcia a fines del siglo XIII : Berenguer de Puigmoltó. Personaje que tras la conquista echa raíces en estas tierras, alcanzando un papel importante en el desarrollo histórico posterior de esta zona incorporada a la corona de Aragón.

El linaje de los Puigmoltó tiene su origen en Cataluña con descendencia en Valencia y Alicante. Su lugar de origen puede ser una masía del municipio de Mediona en el Alt Penedés, una pequeña aldea o llogaret del municipio de Sant Pere de Ribes (Garraf), la antigua cuadra del municipio de Sant Martí Sesgueiola en la Anoia ${ }^{3}$ o bien el lugar de Montroig del ayuntamiento de Pallargues, partido judicial de Cervera, en Lleida. Parece que los descendientes de Berenguer de Puigmoltó radicaron en

1 (Trabajo realizado dentro del proyecto «La bailía general del Reino de Valencia en la época foral medieval» del área de Historia Medieval de la Universidad de Alicante, financiado por la Consellería de Cultura, Educación y Ciencia, dentro del plan valencià de ciència i tecnologia de la Generalitat Valenciana).

2 B. PROTS (ed.), Traiteés du duel judiciare, París 1872, pp. 45-46.

3 VV.AA. Gran Enciclopedia catalana, vol. 12, Barcelona, 1978, p. 177. 
Cocentaina y Bocairente pasando a la villa de Onteniente ya en el siglo $\mathrm{XVI}^{4}$. El apellido Puigmoltó, pese a su trascendencia en época medieval, no se conserva actualmente en la provincia de Alicante, aunque sí en la ciudad de Valencia.

En las distintas luchas que llevan a cabo los grandes señores medievales, los caballeros proporcionan un cuerpo de élite que, además de guerreros, forman un grupo de oficiales a quienes se pueden confiar importantes responsabilidades como los castillos o la protección de las tierras o propiedades conquistadas ${ }^{5}$. Jaime II pone en práctica esta teoría con el caballero Berenguer de Puigmoltó.

El caballero catalán, objeto de nuestro estudio, acompaña a Jaime II de Aragón en la conquista y toma del castillo y ciudad de Alicante en 1296 . El rey, ante la negativa del alcaide del castillo de Alicante a entregar la fortaleza, decide entrar al frente de sus tropas y tomarlo al asalto. Berenguer de Puigmoltó pide al joven Jaime ll que lo deje entrar primero con el fin de salvaguardar su vida ${ }^{6}$, tal vez por su mente pasó el consejo de Aristóteles al rey Alejandro que refleja Ramón Llull en su mítico Llibre de l'orde de cavalleria:

\section{“...dar con generosidad para ganar leal servicio»7}

Pero, ante la propuesta del joven caballero, el rey se niega y entra recibiendo importantes cargas por los defensores del castillo. Inmediatamente Berenguer y otro caballero saltan a primera línea y deciden la batalla a favor de la corona de Aragón.

«...-Ah, senyor! Què serà açò? Lleixatsnos entrar primers.

E lo senyor rei sol no l'escoltà, ans se mès avant; e lo dit En Berenguer de Puigmoltó saltà avant, e un altre cavaller...e En Bereguer de Puigmoltó no es partia del senyor rei, e així mateix feïa d'armes que meravella era." ${ }^{8}$

Puigmoltó no se aparta del rey en la batalla y finalmente, una vez esta decidida, es encargado por Jaime II de la fortaleza recién tomada, aunque el primer alcaide del castillo, en manos de la corona de Aragón, será Ramón Pedro de Urtx ${ }^{9}$. Juntos bajan a la villa posteriormente donde los notables del lugar rinden homenaje al nuevo señor de estas tierras. Cuando Jaime II continuó con el grueso de su ejército camino del sur Berenguer de Puigmoltó quedó en calidad de justicia ${ }^{10}$ cargo otorgado por el rey junto

4 A. y A. GARCÍA CARRAFFA, El solar catalán, valenciano y balear. Vol. III, Librería internacional, San Sebastián 1968, pp. 377 y 378.

5 Maurice KEEN, La caballería, Ariel historia, Barcelona 1986, p. 48.

6 MUNTANER, Crónica, c. CLXXXVIII, ed. Soldevila, Barcelona 1971, p. 834 s.

J.M. DEL ESTAL, Alicante de villa a ciudad, Alicante, 1990, pp. 23-26.

7 R. LLULL, Libre de l'orde de cavalleria, ed. Obres essencials, Barcelona 1957.

8 R. MUNTANER, Les quatre grans cróniques, ed. Soldevila, ed. Selecta Barcelona 1983, pp. 834-835.

9 J.M. DEL ESTAL, Alicante de villa...

10 Ibidem. 
al nombramiento de baile para el caballero Ramón de Capiath. Inmediatamente después de la conquista recibe Puigmoltó una heredad en el raval y otra en en el término de la villa, en concreto una alqueria en Beniçafa y otra en Calcapel que habían pertenecido a Pero Núñez y que le fueron confiscadas ${ }^{11}$.

Puigmoltó intenta mejorar el estado general de la villa y en agosto de 1296 obtiene del monarca aragonés, previa petición suya, la creación de una feria anual durante todo el mes de agosto, con el disfrute de todos los fueros acostumbrados por cuantos mercaderes acudieren a su convocatoria, a excepción de criminales, falsificadores de moneda y salteadores de caminos ${ }^{12}$. En documentos posteriores Jaime II manda regular el arriendo de algunos lugares de la villa a beneficio de monederos de la corona que acuñarían moneda en breve y lo hace al justicia de la ciudad Berenguer de Puigmoltó ${ }^{13}$. También el rey informa sobre cómo actuar en diversos asuntos, como el que atañe al pleito entre Pedro de Leuda y García Jofre de Loaysa ${ }^{14}$. En 1297, un fogoso Puigmoltó, firma una batalla contra Pere Martí de Alcanys ante el procurador Jaime Pérez ${ }^{15}$; cuando el rey conoce del asunto por éste le ordena que impida la lucha, ya que lo prohibían expresamente la Curia Regia y los fueros de Aragón, Valencia, Murcia y Barcelona ${ }^{16}$.

En el año 1300 se percibe un conflicto en el seno de la ciudad alicantina que tiene como protagonista a nuestro caballero, en concreto Jaime II ordena a Ramón Sacoma y a Jaume Bernat que hagan una encuesta para averiguar lo sucedido en el asalto a la casa de Berenguer de Puigmoltó ${ }^{17}$, su casa en Alicante fue asaltada por hombres armados que hieren a los escuderos y a familiares de Berenguer de Puigmoltó. Sin duda el nuevo dominio político de la corona de Aragón en el territorio conllevaría una serie de tensiones sociales propiciadas por el cambio de oligarquía dominante en la política y economía de la villa. A pesar de ello la situación general de la zona conquis-

11 Má.T. FERRER I MALLOL, Organitzaciò y defensa d'un territorio fronterer, la Gobernació d'Oriola en el segle XIV. CSIC, Barcelona, 1990, p.64. En este libro se analiza la labor de Berenguer de Puigmoltó como lugarteniente dełlà Xexona.

12 AMA, armr. 5, lib. 67, fol. 158r. J.M. ESTAL, "Erección por Jaime // de una feria en Alicante", «Ridea», 16 , Alicante, 1975, pp. 153-174. ÍDEM. Alicante de Villa a Ciudad...

13 A.C.A., C, reg. 105, 208 v. (1296, noviembre, 5) DEL ESTAL, El reino de Murcia bajo Aragón, $1 / 2$, doc. 144 , p. 268.

14 A.C.A., C, reg. 340, 40 r. (1296, mayo, 11) DEL ESTAL, ob. cit.

15 Jaime Pérez era hermano del rey Jaime ll y ocupa la procuración del reino de Murcia desde la conquista hasta que pasa esta a manos de Jaime de Jérica. J.V. CABEZUELO PLIEGO, Poder público y administración territorial en el reino de Valencia, 1239-1348. El oficio de la procuración. Tesis, pp. 258-260.

16 A.C.A., C, reg.108, f. 143 v. (1297, julio, 17. Lérida) Este interesante documento demuestra como la oligarquía dominante intenta dirimir sus disputas a la vieja usanza, por medio de duelo, aunque estaban ya prohibidos por ley. La pervivencia de estas costumbres antiguas, a pesar de su primitivismo, no dejan de reflejar cierto romanticismo y desde el punto de vista histórico la pervivencia de una mentalidad caballeresca ya en baja Edad Media.

17 A.C.A., C, reg. 115,228 v. (1300, febrero, 8). 
tada era tranquila y así lo demuestra la satisfacción del rey expresada desde Nápoles a su procurador Jaime de Jérica sobre la tranquilidad y estado pacífico de los reinos de Valencia y Murcia $^{18}$.

Unos meses después, ya en 1298, Puigmoltó es recompensado por sus servicios con una nueva concesión regia, se le concede el Alcacer de la villa de Elche ${ }^{19}$. También en estos momentos el rey le concede la alcaidía de la torre de la Calahorra de Elche informando de ello a Jaime de Jérica ${ }^{20}$, procurador de los reinos de Valencia y Murcia, para que lo tenga como tal ${ }^{21}$. Esta concesión no se lleva término en este momento ante la oposición del alcaide Pero López de Rufes ${ }^{22}$ que había sido amonestado por Jaime II en dos ocasiones por distintos motivos y aunque Puigmoltó queda encargado de la Calahorra en ausencia de López de Rufes pero no cambia todavía de manos la fortaleza ${ }^{23}$.Como persona de la confianza y al servicio del rey sigue recibiendo oficios de administración y gobierno, como en 1301 cuando Jaime II le concede el oficio de merino (encargado de la economía y recaudación de rentas y tributos de un distrito) de Elche ${ }^{24}$; también en 1302, Jaime II ordena a Bernat de Sarriá25, procurador del reino de Murcia, que encargue a Berenguer de Puigmoltó la alcaldía del castillo de Orihuela por un tiempo a beneplácito real, tras la muerte de Guillem de Vilaragut ${ }^{26} \mathrm{con}$ el fin de que no quede vacante, en esta concesión vemos como tampoco se realiza inmediatamente ya que se había concedido previamente a Rodrigo de Biscarra. Hasta 1305 no queda en manos del caballero Puigmoltó el castillo de Orihuela ${ }^{27}$. La confian-

18 A.C.A. c, reg. 113 , fols. 164 v. -165 r. (1299, junio, 10).

19 A.C.A., C, reg. 112, f. 62v. (1298, junio, 22).

20 Jaime de Jérica es un noble cuya familia está emparentada con Jaime I y con Roger de Lauria y es nombrado en la crónica de Muntaner como partícipe de la campaña de conquista del reino de Murcia con Jaime II como indica en su trabajo J.V. CABEZUELO PLIEGO, ob cit. p. 260 y ss. Más sobre este personaje en J.V. CABEZUELO PLIEGO, «De nuevo sobre procuración, frontera y organización defensiva del reino de Valencia frente al islam en el siglo XIV. Jaime de Jérica y Granada" Comunicación Congreso de historia militar de Sevilla 1995. Jaime de Jérica es nombrado procurador de los reinos de Valencia y Murcia el 9 de abril de 1298 cargo que ocupa hasta 1300: A.C.A., c, reg. 196, fol. 183r. Publicado por Mạ.T. FERRER I MALLOL, Organització...Doc. 14.

21 A.C.A., C, reg. 265 , f. 245 r.

22 Este personaje es lugarteniente tras el mandato de Puigmoltó. Mª.T. FERRER I MALLOL; Organització... p. 72.

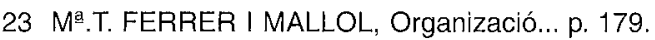

24 A.C.A., C, reg. 198, f. 267 r. (1301, febrero, 25).

25 El estudio más completo que se ha realizado sobre cargos públicos en el antiguo reino de Valencia se puede encontratar en: J.V. CABEZUELO PLIEGO, Poder público y administración territorial en el reino de Valencia, 1239-1348. El oficio de la procuración. Valencia, 1998, Generalitat Valenciana, pp. 421-445. En este trabajo aparecen los procuradores reales con un detallado estudio. Bernat de Sarriá fue señor de grandes extensiones territoriales y tuvo gran influencia en la Curia regia como consejero y amigo de Jaime II.

26 A.C.A., C, reg. 199, f. 86 r. (1302, mayo, 31) Ma.T. FERRER, La Tinença a costum d'Espanya en els castells de la frontera meridional valenciana (segle XIV). Doc, 39. p. 49.

27 M‥T. FERRER I MALLOL, Organització... p. 65. 
za en Berenguer de Puigmoltó como soldado queda patente al otorgarle la tenencia del castillo más importante dellà Xixona. Los documentos reflejan la importancia de los distintos castillos de la zona alicantina, pudiéndose establecer una jerarquía por su dotación económica. El más importante sería el de Orihuela con 7.000 sueldos, seguido por los 5.000 de Alicante, los 2.500 de Elche, quedando Callosa con 1.500 y Guardamar con 800 sueldos $^{28}$.

El mismo año de 1302 encontramos a Berenguer de Puigmoltó como funcionario, desempeña el oficio de lugarteniente del Procurador del reino de Murcia en el proceso y sentencia del pleito que mantienen Guillem Spaeri y el Genovés Otino de Quinto por agresiones $^{29}$. En 1304 se pacta por Puigmoltó y un representante de Castilla indemnizaciones por daños mutuos ${ }^{30}$. El mismo año es nombrado alcaide del castillo de Alhama ${ }^{31}$, donde su actuación suscita quejas que llegan al rey, por lo visto Puigmoltó no deja actuar a los oficiales locales y se mete en asuntos que no son de su incumbencia, también se niega a pagar contribuciones que le correspondían en relación con los bienes confiscados ${ }^{32}$. Jaime II continúa confiando al valeroso soldado y servidor fiel sus plazas militares más importantes, así finalizada la tregua con don Juan Manuel ordena a Bernat de Sarriá que entrege la custodia de los castillos de Aspe, Chinorla y Monovar a Puigmoltó ${ }^{33}$, esta precaución fue innecesaria ya que la tregua se renovó.

Nuestro caballero, demostrando aquí su importancia militar, consta en la relación de efectivos que Jaime Il envía a Ferrer Descortell, Baile general del reino de Murcia, por la que le comunica el número de caballeros armados o alforrados en los lugares más importantes del reino para la defensa del mismo ${ }^{34}$. Berenguer de Puigmoltó tendría dispuestos dos caballos armados y dos alforrados. Esto sitúa a nuestro personaje entre los cuatro caballeros que más aportan a la defensa del reino de Murcia para la corona de Aragón.

Seguramente en la primavera del año 1305 Berenguer de Puigmoltó fue nombrado Lugarteniente del procurador de las tierras dellà Xexona, como tal informa de rumores acerca de una importante incursión granadina hacia el reino de Murcia con unos 800 jinetes que habían sido vistos en Mula y galeras preparadas para combinar un ataque marítimo y terrestre, tras comunicarlo al Procurador vía Cocentaina lo desmiente posteriormente al comprobar la falsedad de los rumores ${ }^{35}$. En agosto de 1305 Jaime II

28 A.C.A., C, reg. 234,77 r. (1306, enero, 19).

29 A.C.A., C, reg. 128 , f. 139 r. (1303, mayo, 18, Valencia).

30 A.C.A., Cartas reales de Jaime II, caja 95, $n^{\circ} 11.635$ (1304, mayo, 31).

31 A.C.A., C, reg. 201 , f. 96 v. (1304, febrero, 1).

$32 M^{2}$.T. FERRER I MALLOL, Organització... p. 65.

33 A.C.A., C, reg. 127., f. 77 r. (1305, abril, 15).

34 A.C.A., C, reg. 235, 22r-23v. (1304, marzo, 1) FERRER... ob. cit. doc. 39, pp. 368-369.

35 M‥T. FERRER I MALLOL, Organització... pp. 66 y 291. 
pide a Puigmoltó y a Gombau de Entença ${ }^{36}$ que no interfieran en los asuntos que competen al baile ya que perjudican sus rentas y derechos ${ }^{37}$, por lo visto no hicieron mucho caso a esta advertencia ya que meses más tarde el rey les increpa por haber inferido en la jurisdicción del baile en asuntos de corsarios, multas y judíos, instando además de forma particular a Puigmoltó a devolver al baile Ferrer Descotell la cantidad de 2.170 sueldos que por estos conceptos había reaudado ${ }^{38}$. Como lugarteniente del procurador para Orihuela y junto con este y el justicia de Orihuela es requerido por el rey para apresar y juzgar a Guillem Togores por los escándalos que produjeron en la villa ${ }^{39}$, la situación venía de la rivalidad entre dos bandos de la ciudad por una parte los Togores y por otra los seguidores de Guillen de Paratge. Se dan actos de bandidaje entre ambos bandos y Puigmoltó intenta apaciguar la situación por medio de alianzas matrimoniales entre ambos clanes que acercaran y resolvieran la conflictividad. Nuestro caballero va aún más lejos y casa a una nieta suya, Berenguerona, con un hijo de Guillen de Togores, este hecho place al rey que entrega 200 monedas de oro como dote para la novia ${ }^{40}$. También en 1305 se da un conflicto típico de tierras de frontera en el caso de la pretensión del rey de pedir un impuesto de marca para los productos castellanos que se ofrecen en las ferias de las tierras de más al sur de Jijona. Este impuesto indemnizaría a Pere de Tonyan a quien le fue apresada una cantidad de doblas en Castilla ${ }^{41}$. Berenguer explica al rey que si el impuesto se carga no acudirán a las ferias los productos castellanos y se perjudicará por tanto el abastecimiento. Vemos a un Berenguer de Puigmoltó ahora ya más funcionario y político que soldado aunque sin olvidar esta función, en 1306 informa al rey del apresamiento de unos granadinos y pide su orden para entregarlos al adelantado de $\mathrm{Murcia}^{42}$, posteriormente Jaime II ordena al procurador que los libere ${ }^{43}$. Otras escaramuzas se resuelven con acciones militares como la persecución de un grupo de castellanos que saquean la huerta de Orihuela para recuperar lo sustraido, hecho este que tiene lugar en Cieza ${ }^{44}$.

En la práctica el procurador no aparece por la zona dellà Xixona ya que los territorios bajo su administración son muy extensos, siendo su lugarteniente quien gobier-

36 Este noble catalán había sido recientemente nombrado Procurador del reino de Valencia en sustitución de Bertran de Canalies, siendo además, el primer oficial que reunía los gobiernos de las partes citra y ultra Sexona como señala en su trabajo J.V. CABEZUELO PLIEGO, ob.cit. p. 308. Es nombrado como procurador en Orihuela en 1296 como recoje E. GISBERT Y BALLESTEROS, Historia de Orihuela, Orihuela 1902, tomo II, p. 10. En esta obra se le nombra también como suegro de Alfonso IV de Aragón.

37 A.C.A., C, reg. 236, f. 16 r. (1305, agosto, 4).

38 A.C.A., C, reg. 236, f. 41 r. (1305, septiembre, 13. Barcelona).

39 A.C.A., C, reg. 236, f. 78 v. (1305, diciembre, 4).

$40 M^{\mathrm{a}}$.T. FERRER I MALLOL, Organització... p. 68.

41 A.C.A., Cartas Reales de Jaime II, caja 20, $n^{\circ}$ 2536, (1305, diciembre, 6).

42 A.C.A., Cartas Reales de Jaime II, caja 165, $n^{\circ} 2099$, (1306, enero, 19).

43 A.C.A., C, reg. 254, f. 126 v. (1306, marzo, 12).

$44 M^{\mathrm{a}}$.T. FERRER I MALLOL, Organitzaci. 
ne efectivamente los territorios asignados. Sabemos que en ese año de 1306 Puigmoltó mantenía la tenencia como alcaide del castillo de Orihuela por la que el baile general del reino de Valencia Ferrer Descortell le tiene que abonar 7.000 sueldos, tal y como establecía Jaime II en su orden datada en $1306^{45}$. A pesar de ello esto no se cumple y Puigmoltó se queja al rey de que el baile general le había rebajado la tenencia del castillo de 7 a 5 mil sueldos lo cual no le permitía por una parte mantenerlo bien, y por otra recuperar dinero propio que había tenido que poner por el año de gran carestía pasado ${ }^{46}$.

Sus dificultades económicas y sus diferencias con el baile valenciano no merman su espíritu de soldado, así en 1306 vemos también como moros de Elche se quejan al rey del apresamiento de 23 de ellos que regresaban a Granada con permiso por carta real al arráez de Crevillente ${ }^{47}$, a pesar de la autorización fueron algunos de ellos detenidos por el activo Berenguer de Puigmoltó ${ }^{48}$. También en otra acción, en este caso contra bandoleros, recupera ganado robado a un vecino de Orihuela ${ }^{49}$. En este año aparece una carta al rey en la que el Consell de Orihuela hace saber al rey del buen servicio, lealtad y buen corportamiento de Berenguer de Puigmoltó y el procurador Gombau de Entença ${ }^{50}$. El mismo día este Consell media ante el rey a favor de Berenguer por la citación para rendir cuentas de ciertos desafueros de los que había sido injustamente acusado ${ }^{51}$. Es una constante en la trayectoria en tierras alicantinas del caballero Puigmoltó la polémica por sus acciones o decisiones.

En este contexto el rey aragonés utiliza a Puigmoltó para llevar a cabo diversos asuntos, así vemos como Jaime II le comisiona para interrogar a vecinos de Alicante, Elche y Jijona sobre disputas por límites municipales ${ }^{52}$. También en 1307 el rey manda por medio del procurador dellà Sexona que ordene a Berenguer de Puigmoltó que no pague nada a los oficiales de Sax hasta que no se aclare la cuestión de este territorio planteada por Don Juan Manuel ${ }^{53}$.

En el año 1307 deja el cargo de lugarteniente y en 1308 Berenguer de Puigmoltó traslada sus actividades a Elche y así aparece en los documentos posteriores ${ }^{54}$.

45 A.C.A., C., reg. 234, 77 r., (1306, abril, 24).

46 A.C.A., Cartas reales de Jaime II, caja 21, $n^{\circ}$ 2684, (1306, mayo, 22).

47 J.R. HINOJOSA MONTALVO, Las tierras alicantinas en la Edad Media, Instituto Juan Gil Albert, Alicante, 1995, pp. 31 y 32. Nos indica como al principio de la conquista de Jaime II el ra'is de Crevillente había mostrado su vasallaje siendo reconocido en su cargo y señorío que formaban Crevillente, Cox, Albatera, Aspe, Chinosa y Monóvar. Un estudio más amplio en P. GUICHARD, Un señor musulmán en la España cristiana: el "rais" de Crevillente (1243-1318), Alicante, 1976.

48 A.C.A., Cartas reales de Jaime II, caja 162, no 1820 (1306, marzo, 1).

49 A.C.A., Cartas reales de Jaime II, caja 110, no 121 (1306, mayo, 25).

50 A.C.A., Cartas reales de Jaime II, caja 21, no 2654 (1306, marzo, 25) J.M. DEL ESTAL, Colección documental del Medievo alicantino, II, doc. 4. Mª.T. FERRER I MALLOL, Organització..., doc. 50, pp. 381-382.

51 A.C.A., Cartas reales de Jaime II, caja 13, doc. 2654 (1306, marzo, 25).

52 A.C.A., C, reg. 138,157 v. (1306, marzo, 28).

53 A.C.A., C, reg. 140, 45 r. (1307, junio, 16).

54 A.C.A., Cartas reales de Jaime II, caja, doc. 3135 (1308, enero, 2). 
Berenguer de Puigmoltó es mandado por el rey, junto con Mateu de Castellsent a esa villa para comunicarle al Consell su intención de darles el fuero de Valencia ${ }^{55}$. Berenguer compra los mil sueldos que el rey había concedido de por vida a Joan de Rocafort sobre las rentas ilicitanas, así como la escribanía de la corte y consell de Elche ${ }^{56}$. Jaime II confirma a Puigmoltó que cada año perciba los citados mil sueldos y mantenga la escribanía ${ }^{57}$. En 1311, tras su labor en la ciudad de las palmeras, se ve que el conflicto con otros cargos está presente como vimos en el pago del castillo de Orihuela, y sigue latente con Ferrer Descortell y el alcaide de la Calahorra, que en ese momento era Pero López de Rufes, ambos personajes son acusados ante el rey por Puigmoltó de tenerle animadversión y de proteger los intereses de familiares suyos. Berenguer de Puigmoltó explica al rey sus actos en Elche donde hace una nueva puerta de la cual quiere dar llave a los moros del lugar, tema este conflictivo ${ }^{58}$.

Posteriormente Jaime II agradece sus servicios y es nombrado en documento real como procurador interino dellà Sexona ${ }^{59}$. En 1312 Jaime II le ordena recabar ciertos impuestos para el baile general Ferrer Descotell ${ }^{60}$. Ahora, junto con este baile, hace saber al rey de su informe a Orihuela para construir atalayas y escuchas por el peligro de incursiones granadinas en esta tierra de frontera ${ }^{61}$. Puigmoltó recibe como alcaide de Orihuela 6.000 sueldos anuales para su mantenimiento por orden del rey en 1313 , a partir de 1316 el castillo es encomendado al noble Acard de Mur ${ }^{62}$. En el año 1314 encontramos a Puigmoltó de nuevo mediando en un comflicto que divide a la sociedad oriolana, ahora los Togores se enfrentan a los Rossell ${ }^{63}$. En este mismo año un Berenguer de Puigmoltó, seguramente su hijo, acude en ayuda del cabildo de de la ciudad de Murcia contra don Juan Manuel, es este Puigmoltó quien recibe la escribanía de Elche, establece una batalla con el vecino de Elche Pere Rodríguez d'Ançano, y probablemente muere en el año $1322^{64}$.

55 A.C.A., C, reg. 140, 92 v.-93 r. (1308, enero, 18).

56 Como veremos al final del artículo Berenguer de Puigmoltó consigue acumular un importante patrimonio durante estos años en los que ocupa importantes puestos en tierras alicantinas.

57 A.C.A., C, reg. 205, 131r.-v. (1308, enero, 22).

58 A.C.A., cartas reales Jaime II, no 4024 (1311, mayo, 17) M‥T. FERRER I MALLOL, Organizació i defensa, p. 69.

59 A.C.A., C, reg. 239, 142 v. (1311, septiembre, 12). Ma .T. FERRER I MALLOL, ob. cit. p. 69.

60 A.C.A., C, reg. 304, 140 r. (1312, abril, 13) J.M. DEL ESTALL, Alicante de villa a ciudad, doc. 115, p. 289.

61 A.C.A., cartas reales de Jaime II, caja 93, no 11.393 (1312, mayo, 3). Mª.T. FERRER I MALLOL, ob.cit. doc. 92, pp. 427-428.

62 A.C.A., C, reg. 234, 91 r-v. (1316, agosto, 25). Acard de Mur es un caballero catalán y barón que fue Procurador general en Orihuela en la primera década del 1300, según E. GISBERT Y BALLESTEROS, ob. Cit. p. 10.

63 M $M^{\mathrm{a}}$.T. FERRER Y MALLOL, Organització... p. 69.

64 Ibidem, p. 70. 
Es en 1320 cuando Jaime II nombra alcaide del castillo de Alicante a Berenguer de Puigmoltó con carácter vitalicio percibiendo los derechos habituales al cargo ${ }^{65}$. Tras casi veinticinco años de servicios desde la toma del castillo de Alicante llega la recompensa para Puigmoltó, una tenencia emblemática, en cuanto a ser el principal puerto de entrada de productos, y vitalicia, en un lugar con gran carga afectiva y hasta nostálgica para nuestro caballero donde ya quedará hasta sus últimos días. Si bien, en 1322, el rey concede esta alcaldía a Bernat de Vilaragut cuando muera Berenguer ${ }^{66}$. A este respecto hay que recordar que el alcaide era nombrado por el rey con una misión militar a cambio de un sueldo anual por su trabajo que era abonado por el Baile general. En el caso del castillo de Alicante era pagado por el baile general de Orihuela. Esta relación, entre rey y alcaide, emanaba del nombramiento y no constituía un vínculo vasallático sino que como hombre de confianza tenía la obligación de cumplir "bien y fielmente» su función. La alcaldía retornaba a manos del rey por tres causas: destitución, renuncia o muerte del alcaide, aunque en todo momento el rey podía revocar al alcaide a su voluntad o dar una tenencia de por vida no sólo a una persona incluso a una familia ${ }^{67}$.

En el castillo de Alicante se vienen realizando obras que tenemos constatadas en 1310 y 1317, pero serían de poca consideración, Jaime II acomete la recaudación de 6.000 sueldos para su reconstrucción por medio de la venta de licencias de exportación pero la mala climatología hace imposible el propósito. En 1327, ya en Alicante, Berenguer de Puigmoltó se queja al secretario del rey, Bernat d'Aversó, de la falta de fondos para el castillo y del incumplimiento del baile en materia económica ${ }^{68}$. Esto es muy habitual en lo referente a los castillos de la zona durante la época medieval ya que un castillo es no sólo un recinto fortificado sino un centro de operaciones que necesita hombres y pertechos suficientes y las continuas necesidades económicas hacen que no siempre estén perfectamente equipados, sobre todo en tiempos de paz.

Este mismo año Jaime II pide al alcaide del Castillo Berenguer de Puigmoltó que facilite al baile general de la Procuración de Orihuela ${ }^{69}$ el cobro del morabatí. Es también en 1327 cuando se escribe por parte de las autoridades de la villa al rey para informarle sobre el lamentable estado en que se encontraba el castillo de Alicante y su temor ante el peligro de incursiones granadinas. Se comenta en esta misiva que torres y muros están derribados en gran parte o en peligro de caer, incluso el albacar por donde entró Jaime II está en ruinas (tal vez un intento de tocar los sentimientos y

65 A.C.A. C, reg. 234, 91 r.-v. (1320, abril, 5) Mํ.T. FERRER I MALLOL, La Tinença... Doc. 11, p. 56.

66 A.C.A., C, reg. 234, 79 r. (1322, abril, 16) M‥T. FERRER I MALLOL, La Tinença... Doc. 13, p. 57.

67 J.R. HINOJOSA MONTALVO, La Clau del regne, Alicante, Patronato Municipal V centenerio, 1990.

68 A.C.A., cartas reales de Jaime II, caja 85, ํํ 10436 (1327, enero, 19) Mํ..T. FERRER I MALLOL, Organització... p. 71.

69 Según la cronología dada por E. GISBERT Y BALLESTEROS, Ob. Cit. p. 24 este Procurador sería Ferrer Gutierre Castell nombrado por Jaime II en 1308. 
recuerdos del rey treinta años después), se pide por último que se ordene al Baile general que envíe lo necesario al alcaide Berenguer de Puigmoltó para terminar con esta situación ${ }^{70}$. Jaime Il contesta que va a hacer revisar toda la fortaleza por Puigmoltó y por el baile para hacerlo restaurar ${ }^{71}$. En realidad el gran deterioro del castillo hace que el consell de la villa de Alicante tema por la seguridad de este punto estratégico marítimo y terrestre para todo el Reino de Valencia. La situación es reflejada por este consell expresando que el alcaide Berenguer de Puigmoltó «no puede mantener las guardias en el albarcar (sic)".

Tras el cambio en el trono aragonés por la muerte de Jaime ll en Barcelona el 2 de noviembre de 1327, en 1330 Alfonso IV notifica a Puigmoltó que ha dado el castillo y el lugar al infante Fernando, por la que ordena la devolución de la fortaleza ${ }^{72}$. Este fue el preludio a la nueva y breve ocupación del castillo y la villa por Castilla en 1356.

La última referencia documental encontrada de Berenguer de Puigmoltó se halla en el libro antiguo de beneficios de la parroquial iglesia de Santa María de Alicante. En 1330 aparece una de las claúsulas del testamento de Berenguer de Puigmoltó por la que dispone que se edifique en dicha iglesia una capilla detrás del altar de Santa María, entre este y el de San Pedro, con altar y advocación a San Blas, estableciendo en ella una capellanía perpetua, dotada anualmente con 400 sueldos reales de Valencia para su mantenimiento y el del clérigo que la sirva. El documento se realiza ante el notario Lorenç Fritos en 1330 asignando 400 sueldos de los cuales 210 serán del censo que tiene con Ramón Sanxovart por unas casas y alfondega que tiene en Alicante. También setenta sueldos de los asignados son de un obrador que tienen esas casas. Otros 50 sueldos más vendrán de un censo que tiene de Berenguer de Vilanova por herencias y por un aljibe de agua que tiene en la huerta de Alicante, el resto hasta 400 sueldos será completado por los albaceas ${ }^{73}$. Vemos como en treinta y cuatro años de estancia de nuestro caballero en tierras alicantinas ha conseguido un importante patrimonio que denota su poder político y económico. Este importante documento ofrece una serie de datos precisos que, contrastados in situ, no pueden ser verificados sin acudir a la prospección arqueológica la capilla de San Blas situada tras el altar mayor existe en santa María como hemos podido comprobar en su archivo ${ }^{74}$ y en la propia iglesia pero no aparece en ella ningún enterramiento, seguramente por reformas o traslados posteriores, esperamos que se lleve a cabo un trabajo arqueológico lo antes posible.

70 A.C.A., cartas reales de Jaime II, caja 76, n 9300. (1329, abril, 1) FERRER I MALLOL, La Tinença... doc. 15, pp. 58-59.

71 A.C.A., C, reg. 250, 16 v. (1327, julio, 27) FERRER I MALLOL, Organització... doc.128, p. 455.

72 A.C.A., C, reg. 480,20 r. (1330, enero, 2).

73 Libro Antiguo de Beneficios de la parroquial Iglesia de Santa María. Instituto Juan Gil Albert, Alicante, 1997. Edición y estudios preliminares por Eduardo Camarero Casas.

74 Libro de registro de la Iglesia de Santa María... 
Aparece un Beltrán de Puigmoltó en la carta de poblamiento para los musulmanes de Ayora como testigo del documento datado en Valencia el 23 de junio de $1328^{75}$. También encontramos en 1432 a Francesc Puigmoltó como subalcaide del castillo de Alicante manteniéndose al mando de la fortaleza hasta 1433.

Observamos, pues, que tras un importante servicio de armas el caballero Berenguer de Puigmoltó queda en estas tierras teniendo un papel determinante como delegado de distintas funciones de administración y gobierno de concesión real. Nuestro caballero reparte sus funciones desde Alicante hacia el sur con presencia en Orihuela y Elche, así como en otros puntos de la zona recién conquistada por Jaime Il. Acaban sus días en la villa de Alicante donde acumula, desde la conquista en 1296, un saneado patrimonio que le permite la creación de una capilla en su principal iglesia; santa María.

75 Enric GUINOT RODRIGUEZ, Cartes de Poblament Medievals valencianes, Generalitat Valenciana, Valencia 1991, p. 261. 